\title{
АЛЛИЛЬНЫЕ ХЛОРИДЫ В КАЧЕСТВЕ ТАКСОГЕНОВ ПРИ КАТИОННОЙ ТЕЛОМЕРИЗАЦИИ
}

Предыдущими исследованиями процессов катионной теломеризации установлен ряд закономерностей в поведении изоолефинов как таксогенов и аллильных галогенопроизводных как телогенов $\left[{ }^{1-7}\right]$. Цель настоящей работы - выявление поведения $\beta$-хлорзамещенных изоалкенов (аллильных хлоридов) в качестве таксогенов при реакциях катионной теломеризации и сотеломеризации.

Вначале исследовались реакции гомотеломеризации наиболее активных аллильных хлоридов, являющихся и изоалкенами. Данные по содержанию хлора в продуктах (табл. 1) и ГЖХ-анализ аддуктов показали, что во всех изученных случаях, кроме 1-хлор-3-метил-2-бутена (I), гомотеломеризация сопровождается образованием дегидрохлорированных продуктов. Гомотеломеризация хлорида (I) протекает с наибольшей скоростью, и дегидрохлорированного продукта образуется не более $10 \%$. В основном получаются гомоаддукт 2-хлор-3-хлорметил-2,6-диметил-5-гептен (II) и высшие продукты.

Далее, для установления закономерностей образования высших продуктов исследовалось изменение относительного содержания моно- и полиаддуктов в зависимости от степени конверсии. Уменьшение содержания моноаддукта в теломере (табл. 1 и 2) показывает, что высшие продукты образуются за счет вторичной реакции моноаддуктов в качестве таксогенов. Экстраполяция этих данных на нулевую степень конверсии показывает, что скорость роста цепи ничтожна.

Таблица 1

Гомотеломеризация аллильных хлоридов *

\begin{tabular}{|c|c|c|c|c|c|}
\hline \multirow[b]{2}{*}{$\begin{array}{c}\text { Аллильное } \\
\text { пронзводное ** }\end{array}$} & \multirow[b]{2}{*}{$\begin{array}{c}\text { Концент- } \\
\text { рация } \\
\mathrm{SnCl}_{4} \text {, } \\
\text { моль/л }^{-}\end{array}$} & \multirow[b]{2}{*}{$\begin{array}{c}\text { Время, } \\
\text { мин }\end{array}$} & \multicolumn{3}{|c|}{ Теломер } \\
\hline & & & $\begin{array}{c}\text { выход, } \\
\%\end{array}$ & $\begin{array}{c}\text { содер- } \\
\text { жание } \\
\text { хлора, } \\
\%\end{array}$ & $\begin{array}{c}\text { содержа- } \\
\text { ние димер- } \\
\text { ной фрак- } \\
\text { ции, \% }\end{array}$ \\
\hline$\left(\mathrm{CH}_{3}\right)_{2} \mathrm{C}=\mathrm{CHCHClCH}_{3}$ & 0,006 & 43 & 39 & 20,8 & 59 \\
\hline$\left(\mathrm{CH}_{3}\right)_{2} \mathrm{C}=\mathrm{C}\left(\mathrm{CH}_{3}\right) \mathrm{CH}_{2} \mathrm{Cl}$ & 0,026 & 23 & 25 & $\begin{array}{l}20,0 \\
26,4\end{array}$ & 58 \\
\hline$\left(\mathrm{CH}_{3}\right)_{2} \mathrm{C}=\mathrm{CHCH}_{2} \mathrm{Cl}$ & 0,015 & 5 & 16 & 31,1 & 65 \\
\hline он же & 0,014 & 15 & 23 & 31,6 & 55 \\
\hline он же & 0,018 & 5 & 35 & 33,9 & 35 \\
\hline он же & 0,018 & 13 & 55 & 32,5 & 27 \\
\hline $\mathrm{CH}_{3} \mathrm{CH}=\mathrm{C}\left(\mathrm{CH}_{3}\right) \mathrm{CH}_{2} \mathrm{Cl}$ & 0,060 & 19 & 17 & 27,0 & 52 \\
\hline
\end{tabular}

* Гомотеломеризация 4-хлор-2,4-диметил-2-пентена и 2-хлор-3-пентена протекает с побочным отщеплением хлористого водорода $\left[{ }^{6}, 7\right]$.

** Использовались кинетически равновесные смеси аллильных изомеров [3,5]. 
Теломеризация 3-хлор-2-метил-1-пропена (IIIr) с аллильными хлоридами

\begin{tabular}{|c|c|c|c|c|c|c|}
\hline \multirow[b]{2}{*}{ Телоген } & \multirow[b]{2}{*}{$\begin{array}{c}\text { Концент- } \\
\text { рация } \\
\mathrm{SnCl}_{4} \text {, } \\
\text { моль/л }\end{array}$} & \multirow[b]{2}{*}{$\begin{array}{c}\text { Время, } \\
\text { мин }\end{array}$} & \multirow[b]{2}{*}{$\begin{array}{c}\text { Выход } \\
\text { тело- } \\
\text { мера, } \\
\%\end{array}$} & \multicolumn{3}{|c|}{ Фракция моноаддуктов } \\
\hline & & & & $\begin{array}{c}\text { выход } \\
\text { от тело- } \\
\text { мера, } \\
\%\end{array}$ & $\begin{array}{c}\text { содер- } \\
\text { жание } \\
\text { хлора, } \\
\%\end{array}$ & $\begin{array}{c}\text { состав по } \\
\text { ГЖХ, } \\
\%\end{array}$ \\
\hline$\left(\mathrm{CH}_{3}\right)_{2} \mathrm{C}=\mathrm{CHCH}_{2} \mathrm{Cl}$ & 0,009 & 27 & 16 & 65 & 35,1 & II $57 ;$ IVr 35 \\
\hline он же & 0,014 & 17 & 24 & 55 & 35,0 & II 55 ; IVr 35 \\
\hline он же & 0,016 & 45 & 39 & 36 & 34,2 & II $54 ;$ IVr 34 \\
\hline $\mathrm{CH}_{3} \mathrm{CH}=\mathrm{CHCH}\left(\mathrm{CH}_{3}\right) \mathrm{Cl}$ & 10,009 & 33 & 27 & 92 & 35,2 & V $98^{*}$ \\
\hline он же & 0,017 & 24 & 50 & 88 & 35,3 & V $98^{*}$ \\
\hline он же & 0,021 & 20 & 65 & 85 & 34,9 & V $98^{*}$ \\
\hline
\end{tabular}

* Эритро-и трео-изомеры 1,2-дихлор-2,4-диметил-5-гептена (V).

Таким образом, можно сказать, что при сотеломеризации изоалкена и аллильного хлорида (I) (схема) образуются, главным образом, моноаддукты (II) и (IV) (являются 2-метил-2-алкенами), которые вступают во вторичную теломеризацию с близкими скоростями (заместители в положениях 5 и 6 оказывают незначительное влияние [8]). При этом относительный выход гомоаддукта (II) зависит от активности алкена.

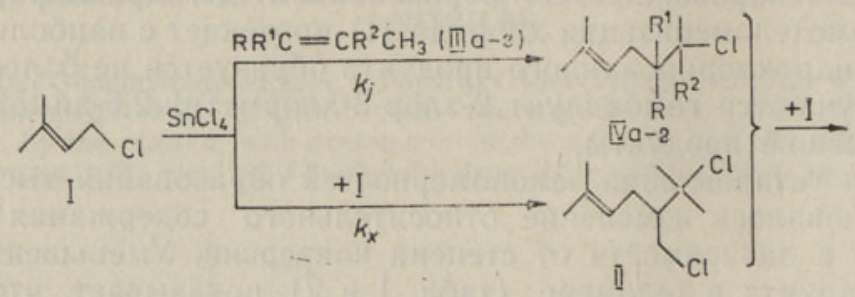

IIIа и IVa: $\mathrm{R}=\mathrm{H} ; \mathrm{R}^{1}, \mathrm{R}^{2}=\mathrm{CH}_{3}$;

ІІІб и IVб : $\mathrm{R}, \mathrm{R}^{1}, \mathrm{R}^{2}=\mathrm{CH}_{3}$;

IIІ и $\mathrm{IV}$ в : R, $\mathrm{R}^{1}=\mathrm{H} ; \mathrm{R}^{2}=\mathrm{CH}\left(\mathrm{CH}_{3}\right)_{2}$;

III и и IVr : R, $\mathrm{R}^{1}=\mathrm{H} ; \mathrm{R}^{2}=\mathrm{CH}_{2} \mathrm{Cl}$.

B табл. 3 приведены данные относительного содержания аддуктов (II) и (IV), определенные в теломеризате методом ГЖХ. В литературе часто приводятся данные фракционирования теломеров и хроматографирования низших аддуктов. Данные теломеризации изоолефинов (IIIaв) с хлоридом (I) $[1,3,9]$ показывают, что полученные значения относительного содержания дихлорида (II) в среднем в 1,5 раза ниже по сравнению с данными табл. 3. По-видимому, при фракционировании теломеров небольшое количество вышекипящего дихлорида не перегонялось.

Поскольку при небольших степенях конверсии изменение соотношения исходных реагентов незначительно, то относительный выход аддуктов (II) и (IV) определяется соотношением констант $k_{j} / k_{x}$. Данные табл. 3 показывают постоянное соотношение аддуктов (II) и (IV) даже до умеренных степеней конверсии. Изученные изоалкены по относительным скоростям образования моноаддуктов при небольших степенях конверсии располагаются в следующий ряд:

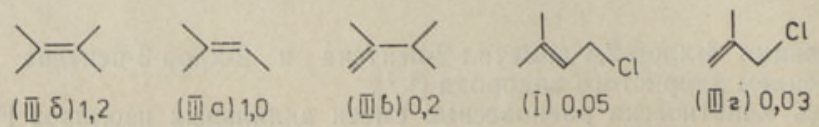


Сотеломеризация 1-хлор-3-метил-2-бутена (I) и алкенов (IIIa-r) с хлоридом (I)

\begin{tabular}{|c|c|c|c|}
\hline Алкен & $\begin{array}{l}\text { Молярное } \\
\text { соотношение } \\
\text { I : III }\end{array}$ & $\begin{array}{c}\text { Конверсия, } \\
\%\end{array}$ & $\begin{array}{c}\text { Относительное } \\
\text { содержание по } \\
\text { ГЖX } \\
\text { II : IV }\end{array}$ \\
\hline $\begin{array}{c}\left(\mathrm{CH}_{3}\right)_{2} \mathrm{C}=\mathrm{C}\left(\mathrm{CH}_{3}\right)_{2} \\
\text { (III6) }\end{array}$ & $\begin{array}{l}1,98: 1 \\
1,99: 1 \\
2,08: 1\end{array}$ & $\begin{array}{r}9 \\
21 \\
15\end{array}$ & $\begin{array}{l}8,5: 91,5 \\
9,0: 91,0 \\
8,3: 91,7\end{array}$ \\
\hline$\underset{\text { (IIIa) }}{\mathrm{CH}_{3} \mathrm{CH}=\mathrm{C}\left(\mathrm{CH}_{3}\right)_{2}}$ & $\begin{array}{l}1,51: 1 \\
1,51: 1 \\
2,01: 1\end{array}$ & $\begin{array}{l}10 \\
15 \\
12\end{array}$ & $\begin{array}{l}7,2: 92,8 \\
7,1: 92,9 \\
10: 90\end{array}$ \\
\hline$\underset{\text { (IIIB) }}{\mathrm{CH}_{2}=} \underset{\text { (IIB }}{\mathrm{C}\left(\mathrm{CH}_{3}\right) \mathrm{CH}\left(\mathrm{CH}_{3}\right)_{2}}$ & $\begin{array}{l}2,80: 1 \\
2,80: 1 \\
1,59: 1\end{array}$ & $\begin{array}{r}8 \\
28 \\
10\end{array}$ & $\begin{array}{l}40: 60 \\
42: 58 \\
31: 69\end{array}$ \\
\hline $\begin{array}{c}\mathrm{CH}_{2}=\underset{\text { (III })}{\mathrm{C}}\left(\mathrm{CH}_{3}\right) \mathrm{CH}_{2} \mathrm{Cl} \\
\text { (III) }\end{array}$ & $\begin{array}{l}1: 2 \\
1,01: 1 \\
1,00: 1\end{array}$ & $\begin{array}{r}11 \\
24 \\
9\end{array}$ & $\begin{array}{l}43: 57 \\
60: 40 \\
61: 39\end{array}$ \\
\hline
\end{tabular}

Небольшое влияние побочных (дегидрохлорирование $2-8 \%$ ) и вторичных процессов на соотношение моноаддуктов, а также невысокая точность хроматографирования позволяют считать полученные значения только приблизительно соответствующими значениям реакционных способностей алкенов.

Результаты работы указывают на влияние стерических препятствий при образовании продуктов присоединения к $\beta$-хлорзамещенным изоалкенам, как и в случае изоолефинов [']. Образование продуктов с несколькими три- и тетразамещенными углеродными атомами в соседних положениях приводит к понижению скорости реакции и «нежеланию» полимеризоваться, но при этом относительная скорость побочных направлений (перераспределение галогеноводорода) увеличивается. Установлено, что при реакциях изоалкенов с аллильным хлоридом (I) на основе относительного содержания дихлорида (II) можно оценить относительную реакционную способность алкена.

\section{Әкспериментальная часть}

Исходные вещества получили и подготовили по ранее описанной методике $[1,3]$. 2,3-Диметил-1-бутен (IIІв) получили дегидратацией 2,3диметилбутан-2-ола, который готовили по Гриньяру из изопропилбромида и ацетона $\left[{ }^{1,10}\right]$. Ректификацией выделили алкен (III) с чистотой $98,5 \%$ по ГЖХ: темп. кип. $55,0^{\circ} \mathrm{C}, d_{4}^{20} \quad 0,6869, n_{D}^{20} \quad 1,3871$. 3-Хлор-2-метил-1-пропен (IIIг) получили фракционированием реактива фирмы MERCK с чистотой $98,5 \%$ по ГЖХ: темп. кип. $72,2^{\circ} \mathrm{C}, \quad n_{D}^{20} \quad 1,4270$.

Опыты по теломеризации проводили с эквимолярными количествами исходных реагентов с добавлением определенного количества $2-6 \%$-ного раствора $\mathrm{SnCl}_{4}$ в 1,2-дихлорэтане при интенсивном перемешивании, поддерживая температуру в колбе $22-24^{\circ} \mathrm{C}$. Методика выделения и анализа продуктов описана в [5]. Данные приведены в табл. 1 и 2. Опыты по определению относительных активностей (табл. 3) проводили по ранее разработанной методике с использованием ГЖХ [4]. При этом в реакционную смесь взвешивали 6-10\% о-дихлорбензола или хлористого бензила и по площади их пиков на хроматограммах вычисляли степень конверсии реагентов. Относительные времена удерживания моноаддуктов при $60^{\circ} \mathrm{C}$ следующие: (II) 3,63 , (IVг) 1,78 , хлористый бензил 1,87 , (IVв) 1,12 , (IVб) 0,97, о-дихлорбензол 1,00 , (V) 1,10 и 0,78 (диастерео- 
изомеры), (IVa) 0,58. Химическое строение моноаддуктов (II, IVa-в) установлено ранее $\left[{ }^{1,3,9}\right]$. ПMР-спектры моноаддуктов (IVr) и (V) характеризуются следующими значениями химических сдвигов, м.д. относительно тетраметилсилана: $1,55-1,70 \mathrm{ClCCH}_{3}, 1,65-1,75=\mathrm{CCH}_{3}, 1,9-$ $2,5 \mathrm{CH}_{2}, 3,70 \mathrm{CH}_{2} \mathrm{Cl}, 5,0-5,2=\mathrm{CH}$ для (IV r), $5,3-5,5=\mathrm{CH}$ для (V), 1,05 $\mathrm{CCH}_{3}$ для (V).

\section{Л И ТЕРА Т У РА}

1. Мукс Э. А., Эрм А. Ю., Лыйвеке И. А., Тенг С. Э., Крумм Л. Л., Лээтс К. В. К изучению ионно-каталитической теломеризацин. XXV. Стерический эффект алкильных заместителей. - Ж. орг. хим., 1988, 24, № 9, 1838-1842.

2. Мукс Э. Сопоставление реакций электрофильного присоединення. Конкурирующие направлення, определяемые строением алкена. - Изв. АН ЭССР. Хим., 1987, 36, № 2, 103-113.

3. Мукс Э. А., Лээтс К. В. К изучению ионно-каталитической теломеризации. XXII. O перераспределении галогеноводорода при теломеризации изоалкенов. - Ж. орг. хим., 1985,21 , № $6,1177-1180$.

4. Мукс Э. А., Эрм А. Ю., Лээтс К. В. К изучению ионно-каталитической теломеризацин. XXIII. Метод определения относительной реакционной способности галогенопроизводных. - Ж. орг. хим., 1986, 22, № 7, 1386-1388.

5. Лээтс K. В., Мукс Э. А. К изучению ионно-каталитической теломеризации. VI. O влиянии строения аллильных изомеров на кннетику и направление реакции. Ж. орг. хим., 1974, 10, № 2, 162-164.

6. Генусов М. Л., Петров А. А. Ионная теломеризация некоторых непредельных соединений с аллильными хлоридами. - Ж. орг. хим., 1965, I, № 12, 2105-2115.

7. Mayr, H., Klein, H., Kolberg, G. Lewis-Säure-katalysierte Additionen 1,3-Alkylsubstituierter Allylkloride an Alkene. - Chem. Ber., 1984, 117, N 8, 2555-2579.

8. Мукс Э., Вийтмаа С., Крумм Л., Лээтс К. Влияние алкильных заместителей в $\gamma$-положении к двойной связи на реакционную способность алкена. - Изв. АН ЭССР. Хим., 1986, 35, № $3,229-230$.

9. Лээтс К., Ранг Х., Чернышев В., Пехк T. О составе продукта теломеризации 1-хлор-3-метил-2-бутена с 2,3-диметил-1-бутеном. - Изв. АН ЭССР. Хим., 1982,31 , № $2,147-148$.

10. Kistiakowski, C. B., Ruhoff, J. R., Smith, H. A., Vanghan, W. E. Heats of organic reactions. III. Hydrogenation of some higher olefins. - J. Amer. Chem. Soc., 1936, 58, 137-145.
Институт химии
Академии наук Эстонской ССР
Поступила в редакцию
31/III 1988

Elvi MUKS, Margarita RAILJAN, Signe TENG, A. ERM, K. LAATS

\section{ALLUULSED KLORIIDID TAKSOGEENIDENA KATIOONSE TELOMERISATSIOONI REAKTSIOONIDES}

$\beta$-kloorasendatud isoalkeenide (allüülsed kloriidid) katioonse telomerisatsiooni reaktsioonides esinevad steerilised takistused, mistōttu praktiliselt ei toimu ahela kasvu reaktsioonid, kuid moodustub dehüdrokloorunud produkte. 1-kloor-3-metüül-2-buteeni reaktsioonil isoalkeenidega vőib dimeeri 2-kloor-3-kloormetüül-2,6-dimetüül-5-hepteeni suhtelise sisalduse järgi monoaduktides hinnata alkeenide suhtelist reaktsioonivõimet.

Elvi MUKS, Margarita RAILJAN, Signe TENG, A. ERM, K. LAATS

\section{ALLYLIC CHLORIDES AS TAXOGENS IN CATIONIC TELOMERIZATION}

In the title reactions steric hindrances suppress chain growth reactions but contribute to the formation of dehydrochlorinated products. In the reactions of 1-chloro-3-methyl-2butene with isoalkenes the relative reactivity of alkenes may be approximately evaluated on the basis of adduct composition. 